\title{
MENGUJI KONSEP DIRI DIBIDANG AKADEMIK SEBAGAI VARIABEL MEDIATOR DARI PENGARUH PERSEPSI ATAS KETERLIBATAN ORANG TUA TERHADAP HASIL BELAJAR EKONOMI SISWA KELAS XI IPS SMAN SE KOTA MALANG
}

\author{
Arief Rafsanjani \\ Program Studi Pendidikan Akuntansi \\ Universitas Negeri Malang \\ Malang, Indonesia \\ e-mail: ariefrafs@gmail.com
}

\begin{abstract}
Abstrak
Tujuan dari penelitian ini adalah untuk menguji pengaruh persepsi atas keterlibatan orangtua terhadap hasil belajar ekonomi pada siswa SMA, dan untuk menguji apakah konsep diri dibidang akademik berfungsi secara signifikan sebagai variabel mediator pengaruh persepsi keterlibatan orangtua terhadap hasil belajar ekonomi pada siswa SMA. Penelitian ini termasuk jenis penelitian eksplanasi (explanatory research). Penelitian ini merupakan penelitian cross sectional, dimana penelitian ini untuk memperoleh data dari responden pada periode waktu tertentu (data are gathered just once). Populasi dalam penelitian ini adalah seluruh siswa kelas XI Jurusan IPS Tahun Pelajaran 2012/2013 di SMA Negeri di Kota Malang. Penetapan jumlah sampel untuk menjadi responden dalam penelitian ini dilakukan berdasarkan kriteria bahwa sampel memiliki katakteristik estimator yang baik (characteristics of good estimator) dan bermanfaat sebagai penaksir yang baik terhadap populasi Pengambilan sampel sekolah juga memperhatikan sebaran semua SMA Negeri di tiap kecamatan di Kota Malang, yaitu 5 sekolah (50\%) berada di Kec. Klojen, 3 sekolah (30\%) berada di Kec. Lowokwaru, dan 2 sekolah (20\%) berada di Kec. Kedungkandang.

Berdasarkan hasil penelitian yang telah dilakukan diperoleh kesimpulan yaitu terdapat pengaruh positif signifikan persepsi atas keterlibatan terhadap hasil belajar ekonomi pada siswa SMAN se Kota Malang, demikain halnya variabel konsep diri dibidang akademik berfungsi secara signifikan sebagai variabel mediator dari pengaruh persepsi keterlibatan orangtua terhadap hasil belajar ekonomi pada siswa SMA. Namun peran variabel konsep diri dibidang akademik dalam model penelitian ini merupakan partial mediation variable atau merupakan variabel yang memediasi sebagian dari pengaruh persepsi atas keterlibatan orang tua terhadap hasil belajar sehingga ada variable lain yang juga turut memediasi hubungan kausal tersebut yang tidak diteliti dalam model ini

Kata Kunci : Konsep diri, keterlibatan orang tua, hasil belajar,
\end{abstract}

Abstract

The purpose of this study was to examine the effect of the perception of parental involvement on learning outcomes of economics at high school students, and to test whether self-concept in academic functioning significantly as mediator variables influence the perception of parental involvement on learning outcomes of economics at high school students. This research includes the study of explanation (explanatory research). This study is a cross-sectional, where the study was to obtain data from respondents in a certain time period (data are Gathered just once). The population in this study were all students of class XI IPS courses in the academic year $2012 / 2013$ in high schools in Malang. Determination of the number of samples to be respondents in this study is done based on the criteria that the sample has katakteristik

61 Arlef Rafsanjan i 
estimator good (characteristics of good estimator) and useful as predictors for the good of the population Sampling schools also pay attention to the distribution of all high schools in every district in Malang, namely 5 schools $(50 \%)$ are located in the district. Klojen, 3 schools $(30 \%)$ are located in the district. Lowokwaru, and two schools (20\%) are located in the district. Kedungkandang.

Based on the research that has been done it is concluded that there is a significant positive effect perceptions of involvement on learning outcomes of economics at high school students as the city of Malang, demikain as variable self concept in academic functioning significantly as a variable mediator of the effects of the perception of parental involvement on learning outcomes of the economy high school student. But the role in academic self-concept variables in our model is a partial mediation is variable or variables that mediate some of the effects of the perception of parental involvement on learning outcomes so that there are other variables that also contribute to mediate the causal relationship is not examined in this model

Keywords: Self-concept, parental involvement, learning outcomes,

\section{PENDAHULUAN}

Belajar dan hasil belajar merupakan dua unsur yang saling bekaitan, yaitu belajar merupakan input dan prestasi belajar yang menjadi outputnya. Bisa dikatakan bahwa keberhasilan belajar seseorang dapat dilihat dari hasil belajarnya. Untuk lebih memahami tinjauan prestasi belajar dimulai belajarnya. Belajar merupakan perubahan kelakuan berkat pengalamanpengalaman ketika belajar membawa suatu perubahan dengan individu. Perubahan itu tidak hanya dengan perubahan mengenai jumlah pengetahuan melainkan dalam bentuk kecakapan, kebiasaan sikap, pengertian, minat, penyesuaian mengenai gejala aspek organisme atau pribadi seseorang. Pengertian lain mengemukakan bahwa belajar adalah serangkaian kegiatan jiwa raga psikopisik menuju perkembangan pribadi manusia seutuhnya yang menyangkut unsur cipta, rasa dan karsa kognitif dan psikomotor sebagai hasil dari pengalaman, pengetahuan, prilaku individu kearah kedewasaan Sardiman (2006).

Salah satu faktor yang berpengaruh terhadap hasil belajar yang dicapai siswa adalah keterlibatan orang tua. Keterlibatan orang tua mencerminkan sejauh mana orang tua hadir dan menyisipkan diri mereka ke dalam kehidupan anak-anaknya (Gonzalez \& Wolters, 2006). Keterlibatan orangtua juga termasuk komunikasi antara orang tua dan guru (Deslandes et al., 1997); partisipasi orang tua dalam kegiatan-kegiatan sekolah seperti pertemuan orang tua dengan guru (Miedel dan Reynolds, 1999); bantuan yang diberikan orang tua ketika anaknya mendapat PR dari sekolah (Shumow dan Miller, 2001); dan juga berarti perilaku orang tua dirumah dan disekolah dengan tujuan untuk membantu pengalaman belajar anak (Bronfenbrenner, 1986; Galal-El-Dean, 1994). Epstein (1988) mengemukakan bahwa keterlibatan orang tua memiliki peran penting dalam pencapaian pendidikan anak. Semakin peduli orang tua, akan semakin tinggi bantuan dan dukungan yang diberikan, dan semakin baik pencapaian keberhasilan pendidikan anak.

Penelitian yang telah dilakukan oleh Kim (2002), menghasilkan temuan bahwa terdapat hubungan signifikan antara keterlibatan orangtua dan prestasi yang dicapai siswa di sekolah. Van Voorhis (2003) mengemukakan bahwa siswa memperoleh capaian akademik yang lebih tinggi ketika orang tua memberikan bantuan dalam pengerjaan tugas-tugas di rumah. Hal yang sama diungkapkan oleh Lamborn et al., (1992) bahwa bantuan orang tua yang diberikan ketika siswa akan mengambil keputusan berhubungan dengan capaian siswa dibidang akademik. Akan tetapi, dalam beberapa penelitian lainnya ditemukan bahwa tidak terdapat bukti signifikan bahwa keterlibatan orang tua berpengaruh langsung terhadap hasil belajar siswa (Bobbett et al., 1995; Keith et al,. 1986; Okpala dan Smith, 2001), dan bahkan terdapat hubungan negatif diantara dua variabel tersebut (Deslandes et al., 1997; Sui-Chu dan 
Vol. 4 No. 2 Desember 2016

Willms, 1996).

Tidak adanya konsistensi hasil temuan-temuan tersebut disinyalir merupakan hasil dari adanya pengaruh tidak langsung keterlibatan orang tua terhadap hasil belajar siswa (El-Fattah, 2006). Tidak ditemukannya bukti pengaruh langsung keterlibatan orang tua terhadap hasil belajar siswa mungkin disebabkan oleh adanya variabel lain yang menjadi mediasi atau perantara diantara dua variabel tersebut (Keith et al., 1986).

Eccles (2005) menduga bahwa pengaruh keterlibatan orang tua terhadap hasil belajar di mediasi oleh konsep diri siswa dalam kemampuan akademiknya. Dugaan ini didasarkan pada sebuah model yaitu the expectancy-value model of achievement (Eccles, 1983; Wigfield, 1994), keinginan untuk menggapai kesuksesan salah satunya dipengaruhi oleh kepercayaan atas kemampuan yang dimiliki yang selanjutnya dikenal dengan istilah konsep diri. Selanjutnya, konsep diri salah satunya dipengaruhi secara langsung oleh keterlibatan orang tua (Eccles dan Wigfield, 2002). Dugaan Eccles (2005) tersebut didasari sebuah argumen bahwa keterlibatan orang tua mempengaruhi kepercayaan diri siswa akan kemampuan yang dimilikinya, yang kemudian berdampak pada hasil pencapaian belajar siswa di sekolah. Akan tetapi dugaan tersebut belum teruji secara empiris karena Eccles (2005) hanya menarik sebuah hipotesis bahwa pengaruh keterlibatan orang tua terhadap hasil belajar di mediasi oleh konsep diri siswa dalam kemampuan akademiknya berdasarkan the expectancy-value model of achievement.

Hal yang dikemukakan oleh Eccles $(1983,2005)$ dan Wigfield (1994, 2002) didukung oleh beberapa penelitian lain yang menyatakan bahwa keterlibatan orang tua berpengaruh positif pada konsep diri yang dimiliki siswa (Juang dan Silbereisen's, 2002; Hung, 2005; Grolnick dan Slowiaczek, 1994, Marchant et al., 2001; GonzalezDeHass et al., 2005), dan konsep diri

\section{Ekuitas - Jurnal Pendidikan Ekonomi}

siswa secara langsung mempengaruhi prestasi akademik yang dicapai (Guay et al., 2003; Moreano, 2004; Marsh, 2006; Pajares, 2000).

Konsep diri adalah pandangan umum tentang diri sendiri di berbagai set domain tertentu dan persepsi berdasarkan pengetahuan diri dan evaluasi nilai dibentuk melalui pengalaman dalam kaitannya dengan lingkungan seseorang (Eccles, 2005). Konsep diri dibidang akademik merupakan evaluasi diri seseorang mengenai kemampuan atau domain akademik tertentu (Trautwein, et al. 2006). Dengan kata lain, Konsep diri dibidang akademik adalah bagaimana siswa melakukan pekerjaan sekolah atau perasaan tentang diri mereka sebagai pelajar (Guay et al., 2003; Harter, 1998).

Dari hasil kajian dari penelitianpenelitian yang telah dipaparkan diatas, maka penelitian ini dirasa perlu dilakukan untuk menindaklanjuti penelitian sebelumnya yaitu melakukan pengujian secara empiris terhadap dugaan Eccles (2005) bahwa pengaruh keterlibatan orang tua terhadap hasil belajar di mediasi oleh konsep diri siswa dalam kemampuan akademiknya. Sehingga dalam penelitian kali ini, peneliti ingin menekankan pada pengujian untuk membuktikan dugaan bahwa terdapat pengaruh tidak langsung keterlibatan orang tua terhadap hasil belajar, yaitu di mediasi oleh konsep diri siswa dibidang akademik. Oleh karena itu peneliti ingin mengkajinya dalam sebuah penelitian yang berjudul menguji konsep diri dibidang akademik sebagai variabel mediator dari pengaruh persepsi atas keterlibatan orang tua terhadap hasil belajar ekonomi siswa kelas XI IPS SMAN Se Kota Malang"

\section{METODE}

Secara umum penelitian ini bertujuan untuk mendeskripsikan dan menganalisis hubungan antara tiga variabel. Penelitian ini termasuk jenis penelitian eksplanasi (explanatory research). Penelitian ini merupakan penelitian cross sectional, dimana penelitian ini untuk memperoleh data dari responden pada periode waktu 
Vol. 4 No. 2 Desember 2016

tertentu (data are gathered just once). Hasil penelitian ini diharapkan dapat memberikan penjelasan tentang bagaimana pengaruh keterlibatan orang tua terhadap hasil belajar secara langsung maupun tidak langsung yang dimediasi oleh konsep diri dibidang akademik sebagaimana yang didiskusikan dalam argumen teori. Unit analisis penelitian ini ini adalah siswa SMA kelas XI IPS.

Populasi dalam penelitian ini adalah seluruh siswa kelas XI Jurusan IPS Tahun Pelajaran 2012/2013 di SMA Negeri di Kota Malang. Jumlah kesuluruhan populasi dalam penelitian ini adalah 2939. Berdasarkan sebaran dan jumlah populasi, teknik pengambilan sampel yang digunakan dalam penelitian ini adalah Multistage Random Sampling. Tahap pertama dipilih SMA yang akan menjadi sampel penelitian secara random. Tahap berikutnya, dari SMA yang telah terpilih menjadi sampel penelitian akan dipilih responden penelitian dari siswa kelas XI IPS secara random.

Penetapan jumlah sampel untuk menjadi responden dalam penelitian ini dilakukan berdasarkan kriteria bahwa sampel memiliki katakteristik estimator yang baik (characteristics of good estimator) dan bermanfaat sebagai penaksir yang baik terhadap populasi. Formulasi yang dipergunakan untuk menerapkan jumlah sampel adalah sampling estimasi proporsi tanpa pengulanagn (sampling without replacement) dengan tingkat kesalahan sebesar $5 \%$ yang digunakan oleh Cochran (1991). Pengambilan sampel untuk sekolah yang akan diteliti dilakukan secara acak dengan mengambil 6 SMA Negeri yang ada di kota malang. Hal ini dilakukan dengan alasan bahwa semua SMA Negeri di Kota Malang (10 SMA Negeri) memiliki karakteristik yang tidak jauh berbeda yang tampak dari status akreditasi yang dimiliki oleh semua SMA Negeri tersebut adalah "A".

Pengambilan sampel sekolah juga memperhatikan sebaran semua SMA Negeri di tiap kecamatan di Kota

64 | Arlef Rafsanjan i

\section{Ekuitas - Jurnal Pendidikan Ekonomi}

Malang, yaitu 5 sekolah (50\%) berada di Kec. Klojen, 3 sekolah (30\%) berada di Kec. Lowokwaru, dan 2 sekolah (20\%) berada di Kec. Kedungkandang. Berdasarkan sebaran tersebut, pengambilan acak dilakukan dan didapat 6 SMA Negeri yaitu tiga sekolah di Kec. Klojen (SMAN 1, SMAN 2 dan SMAN 5), dua sekolah di Kec. Lowokwaru (SMAN 7 dan SMAN 8), dan satu sekolah di Kec. Kedungkandang (SMAN 6). Terakhir dilakukan pengambilan sampel siswa secara acak di tiap sekolah yang terpilih menjadi sampel, yaitu sebanyak 291 siswa dari 6 sekolah sampel.

Pengambilan sampel untuk sekolah yang akan diteliti dilakukan secara acak dengan mengambil 6 SMA Negeri yang ada di kota malang. Hal ini dilakukan dengan alasan bahwa semua SMA Negeri di Kota Malang (10 SMA Negeri) memiliki karakteristik yang tidak jauh berbeda yang tampak dari status akreditasi yang dimiliki oleh semua SMA Negeri tersebut adalah " $A$ ".

Pengambilan sampel sekolah juga memperhatikan sebaran semua SMA Negeri di tiap kecamatan di Kota Malang, yaitu 5 sekolah (50\%) berada di Kec. Klojen, 3 sekolah (30\%) berada di Kec. Lowokwaru, dan 2 sekolah (20\%) berada di Kec. Kedungkandang. Berdasarkan sebaran tersebut, pengambilan acak dilakukan dan didapat 6 SMA Negeri yaitu tiga sekolah di Kec. Klojen (SMAN 1, SMAN 2 dan SMAN 5), dua sekolah di Kec. Lowokwaru (SMAN 7 dan SMAN 8), dan satu sekolah di Kec. Kedungkandang (SMAN 6). Terakhir dilakukan pengambilan sampel siswa secara acak di tiap sekolah yang terpilih menjadi sampel, yaitu sebanyak 291 siswa dari 6 sekolah sampel.

Adapun teknik analisis yang digunakan dalam penelitian ini adalah teknik analisis jalur (path analysis). Tujuan penggunaan tehnik analisis jalur menurut Riduwan (2007:2) adalah untuk mengetahui pengaruh langsung maupun tidak langsung seperangkat variabel bebas (eksogen) terhadap variabel terikat (endogen).

1. Asumsi Analisis Jalur (Path Analysis) Asumsi-asumsi yang mendasari 
Vol. 4 No. 2 Desember 2016

penggunaan analisis jalur adalah sebagai berikut:

a) Hubungan antar variabel adalah linier, adaptif dan data berdistribusi normal.

b) Hubungan antar variabel merupakan sebab akibat satu arah (rekursif)

c) Variabel endogen minimal berskala interval

d) Instrument penelitian harus valid dan reliable

2. Pengujian dengan Tehnik Analisis Jalur (Path Analysis)

3. Model path analysis yang digunakan dalam penelitian ini mengadopsi model causal steps milik Baron dan Kenny (1986). Dalam model tersebut dapat diketahui apakah variabel $\mathrm{M}$ berfungsi sebagai mediator secara penuh (full/completely mediation) atau mediator sebagian (partial mediation). Sedangkan untuk menguji apakah variabel $M$ tersebut berfungsi secara

\section{Ekuitas - Jurnal Pendidikan Ekonomi}

signifikan atau tidak sebagai variabel mediator, dilakukan uji Sobel (Sobel Test).

\section{HASIL DAN PEMBAHASAN}

\section{Persepsi atas Keterlibatan \\ Orang Tua}

Deskripsi data variabel persepsi

atas keterlibatan orang tua diperoleh melalui angket yang dibagikan dan telah diisi oleh responden. Dalam angket tersebut terdapat 18 butir pernyataan untuk mengukur 6 indikator, masingmasing pernyataan memiliki 4 alternatif jawaban dengan skor 1 4. Dari data yang terkumpul, diketahui total skor tertinggi yang diperoleh responden adalah 61 dan terendah 19 dengan mean 42,24 . Data-data tersebut dapat dilihat dalam tabel berikut:

Tabel 1 Distribusi frekuensi persepsi atas keterlibatan orang tua

\begin{tabular}{lllll}
\hline No & Kategori & Rentangan Skor & Frekuensi & $\begin{array}{c}\text { Persentase } \\
\text { (\%) }\end{array}$ \\
\hline 1 & Sangat Tinggi & $50,8-61,3$ & 52 & 17,81 \\
\hline 2 & Tinggi & $40,2-50,7$ & 110 & 39,04 \\
\hline 3 & Rendah & $29,6-40,1$ & 114 & 37,68 \\
\hline 4 & Sangat Rendah & $19-29,5$ & 16 & 5,48 \\
\hline
\end{tabular}

Sumber: data primer diolah (lampiran 5)

Berdasarkan hasil distribusi frekuensi pada table 1, dapat dijabarkan bahwa dari 292 siswa yang menjadi sampel penelitian, 52 siswa atau sebesar $17,81 \%$ mempersepsi keterlibatan orang tua mereka dalam pendidikan sangat tinggi, 110 siswa atau sebesar 39,04\% mempersepsi keterlibatan orang tua mereka dalam pendidikan tinggi, 114 siswa atau sebesar 37,68\% mempersepsi keterlibatan orang tua mereka dalam pendidikan rendah dan 16 siswa atau sebesar $5,48 \%$ mempersepsi keterlibatan orang tua mereka dalam pendidikan sangat rendah. Rata-rata siswa yang menjadi sampel penelitian memperoleh skor 42,24 yang menunjukan bahwa persepsi atas keterlibatan orang tua dalam pendidikan berada pada kategori tinggi.

Tabel 2 Distribusi frekuensi persepsi atas keterlibatan orang tua

\begin{tabular}{lllll}
\hline No & Indikator & Item & Mean & $\begin{array}{l}\text { Std. } \\
\text { Deviasi }\end{array}$ \\
\hline \multirow{2}{*}{1} & Parenting & 1 & 3.1473 & 0.8345 \\
\cline { 3 - 5 } & 2 & 2.7226 & 0.8705 \\
\hline
\end{tabular}

65|Arlef Rafsanjan i 


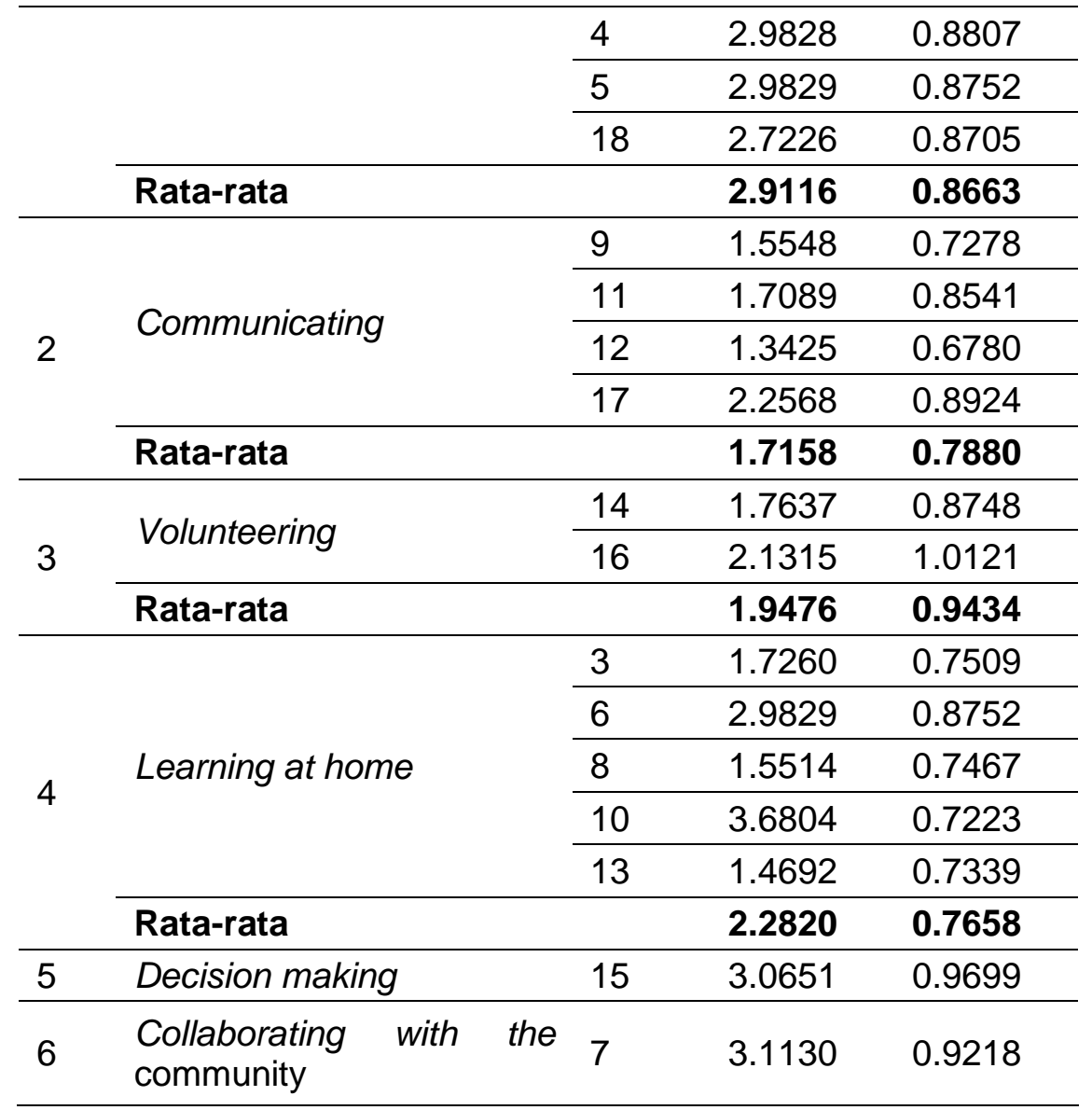

Sumber: data primer diolah (lampiran 5)

Dari table 2 diatas, dapat dilihat bahwa nilai mean menjelaskan rata-rata jawaban responden untuk masingmasing item pernyataan pada tiap indicator variabel persepsi atas keterlibatan orang tua. Pada indicator parenting memiliki skor rata-rata yang cukup tinggi yaitu 2,91. Hal ini menunjukan bahwa siswa rata-rata merasa sering mendapatkan dukungan dan bantuan dari orang tua untuk mencapai hasil pendidikan yang optimal disekolah. Pada indicator communicating memiliki skor rata-rata yang cenderung rendah yaitu 1,72. Hal ini menunjukan bahwa siswa rata-rata merasa bahwa komunikasi yang dilakukan orang tua dan guru, serta komunikasi dengan orang tua siswa yang lain jarang terjadi. Pada indicator volunteering memiliki skor rata-rata yang cenderung rendah yaitu 1,95. Hal ini menunjukan bahwa rata-rata siswa merasa bahwa orang tua jarang terlibat langsung atau menghadiri acara atau kegiatan yang dilakukan sekolah . pada indicator learning at home memiliki skor rata-rata yang cenderung rendah yaitu 2,28. Hal ini menunjukan bahwa rata-rata siswa merasa jarang mendapatkan bantuan dari orang tua ketika belajar dirumah, seperti saat mengerjakan PR. Pada indicator cecision making memiliki skor rata-rata yang cukup tinggi yaitu 3,06. Hal ini menunjukan bahwa rata-rata siswa merasa orang tua sering berpartisipasi dalam pengambilan kebijakan sekolah yang melibatkan orang tua, seperti turut aktif menghadiri rapat komite sekolah. Pada indicator collaborating with the community memiliki skor rata-rata yang cukup tinggi yaitu 3,11 . Hal ini menunjukan bahwa rata-rata siswa merasa orang tua sering ikut aktif berpartisipasi dalam kegiatan yang 
Vol. 4 No. 2 Desember 2016

memberikan kontribusi pada sekolah.

2. Konsep Diri dibidang Akademik

Deskripsi data variabel konsep diri dibidang akademik diperoleh melalui angket yang dibagikan dan telah diisi oleh responden. Dalam angket tersebut terdapat 20 butir pernyataan untuk mengukur 2 indikator, masing-

\section{Ekuitas - Jurnal Pendidikan Ekonomi}

masing pernyataan memiliki 4 alternatif jawaban dengan skor 1 4. Dari data yang terkumpul, diketahui total skor tertinggi yang diperoleh responden adalah 74 dan terendah 39 dengan mean 59,68. Data-data tersebut dapat dilihat dalam tabel berikut:

Tabel 3 Distribusi frekuensi konsep diri dibidang akademik

\begin{tabular}{lllll} 
No & Kategori & Rentangan Skor & Frekuensi & Persentase (\%) \\
\hline 1 & Sangat Tinggi & $65,28-74,03$ & 58 & 19,86 \\
\hline 2 & Tinggi & $56,52-65,27$ & 154 & 52,74 \\
\hline 3 & Rendah & $47,76-56,51$ & 67 & 22,95 \\
\hline 4 & Sangat Rendah & $39-47,75$ & 13 & 4,45 \\
\hline
\end{tabular}

Sumber: data

Berdasarkan hasil distribusi frekuensi pada table 4.3, dapat dijabarkan bahwa dari 292 siswa yang menjadi sampel penelitian, 58 siswa atau sebesar 19,86\% memiliki konsep diri dibidang akademik yang sangat tinggi, 154 siswa atau sebesar $52,74 \%$ memiliki konsep diri dibidang akademik yang tinggi, 67 siswa primer

diolah atau sebesar 22,95 \% memiliki konsep diri dibidang akademik yang rendah dan 13 siswa atau sebesar $4,45 \%$ memiliki konsep diri dibidang akademik yang sangat rendah. Rata-rata siswa yang menjadi sampel penelitian memperoleh skor 59,68 yang menunjukan bahwa mereka memiliki konsep diri dibidang akademik yang tinggi.

Tabel 4 Distribusi frekuensi konsep diri dibidang akademik

\begin{tabular}{|c|c|c|c|c|}
\hline No & Indikator & Item & Mean & $\begin{array}{l}\text { Std. } \\
\text { Deviasi }\end{array}$ \\
\hline \multirow{11}{*}{1} & \multirow{10}{*}{ Academic Confidence } & 1 & 2.6952 & 0.5917 \\
\hline & & 3 & 2.3767 & 0.6051 \\
\hline & & 7 & 2.5533 & 0.6377 \\
\hline & & 9 & 2.7352 & 0.5729 \\
\hline & & 11 & 2.9583 & 0.5061 \\
\hline & & 14 & 2.9583 & 0.5061 \\
\hline & & 17 & 3.7226 & 0.4853 \\
\hline & & 18 & 2.8425 & 0.7705 \\
\hline & & 19 & 2.7842 & 0.6019 \\
\hline & & 20 & 2.7568 & 0.7028 \\
\hline & Rata-rata & & 2.8383 & 0.5980 \\
\hline \multirow{3}{*}{2} & \multirow{3}{*}{ Academic Effort } & 2 & 2.7671 & 0.5749 \\
\hline & & 4 & 2.5890 & 0.6752 \\
\hline & & 5 & 3.0274 & 0.6416 \\
\hline
\end{tabular}




\begin{tabular}{llll}
\hline & 6 & 3.1993 & 0.7576 \\
\cline { 2 - 4 } & 8 & 2.8151 & 0.7084 \\
\cline { 2 - 4 } & 10 & 3.6976 & 0.5031 \\
\cline { 2 - 4 } & 12 & 3.3253 & 0.7229 \\
\hline 13 & 3.6301 & 0.5805 \\
\hline Rata-rata & 15 & 2.8425 & 0.7705 \\
\cline { 2 - 4 } & & 3.5822 & 0.6396 \\
\hline
\end{tabular}

Sumber: data primer diolah

Dari table 4 diatas, dapat dilihat bahwa nilai mean menjelaskan rata-rata jawaban responden untuk masingmasing item pernyataan pada tiap indicator variabel konsep diri dibidang akademik. Pada indicator academic yang dimilikinya dirasa cukup baik. Pada indicator academic effort juga memiliki skor rata-rata yang cukup tinggi yaitu 3,15. Hal ini menunjukan bahwa rata-rata siswa merasa memiliki komitmen dan telah berusaha untuk melakukan tugasnya sebagai siswa dengan baik.

3. Variabel Hasil Belajar Ekonomi

Deskripsi data variabel hasil belajar ekonomi diperoleh melalui hasil ujian tengah semester genap 2012/2013 pada mata pelajaran ekonomi yang dilakukan oleh dapat dilihat dalam tabel confidence memiliki skor rata-rata yang cukup tinggi yaitu 2,84. Hal ini menunjukan bahwa rata-rata siswa cukup percaya diri (confidence) bahwa kemampuan akademik

masing-masing sekolah. Dari data yang terkumpul, diketahui total skor tertinggi yang diperoleh responden adalah 100 dan terendah 45 dengan mean 81,17. Dari data yang diperoleh dapat diklasifikasikan berdasarkan kriteria ketuntasan minimum (KKM) yang ditetapkan sekolah yaitu 75 menjadi dua kategori, yaitu responden yang lulus dan yang harus mengikuti remedial. Datadata tersebut

berikut:

Tabel 6 Distribusi frekuensi hasil belajar

\begin{tabular}{lllll}
\hline No & Kategori & KKM & Frekuensi & Persentase (\%) \\
\hline 1 & Lulus & 75 & 229 & 78,42 \\
\hline 2 & Remidial & $<75$ & 63 & 21,58 \\
\hline & Sumber: data primer diolah & &
\end{tabular}

Berdasarkan hasil distribusi frekuensi pada table 4.5, dapat dijabarkan bahwa dari 292 siswa yang menjadi sampel penelitian, 229 siswa atau sebesar 78,42 \% mencapai kriteria ketuntasan minimal atau lulus, dan 63 siswa atau sebesar $21,58 \%$ yang tidak mencapai kriteria ketuntasan minimal sehingga harus mengikuti remidial. Rata-rata siswa yang menjadi sampel penelitian memperoleh skor 81,17 yang menunjukan bahwa mereka telah mencapai kriteria ketuntasan minimal atau dapat dinyatakan lulus.

Uji hipotesis pertama $(\mathrm{H} 1)$

68 | Arlef Rafsanjan i 


\section{Vol. 4 No. 2 Desember 2016}

dilakukan untuk mengetahui hubungan kausalitas persepsi atas keterlibatan orang tua dengan hasil belajar ekonomi. Dari hasil analisis data (table 4.11) diketahui bahwa variabel persepsi atas keterlibatan orang tua memiliki tingkat signifikansi $<0,01$ dan koefisien positif. Hal ini menunjukan bahwa hipotesis pertama $(\mathrm{H} 1)$ pada penelitian ini diterima pada tingkat signifikansi $1 \%$, artinya ada pengaruh positif signifikan persepsi atas keterlibatan terhadap hasil belajar ekonomi.

Pada pengujian hipotesis kedua dapat diketahui pengaruh langsung persepsi atas keterlibatan orang tua terhadap hasil belajar maupun pengaruh tidak langsung melalui variabel mediator (konsep diri dibidang akademik) sebagai berikut:

a. Pengaruh Langsung (jalur $\left.c^{\prime}\right)=0.427$ dengan $p$-value $<$ 0,01

b. Pengaruh Tidak Langsung (jalur $a^{*} b$ ) $=0,210 \times$ $0,783=0,16443$ dengan $p$-value $<$ 0,01

c. Pengaruh Total $(\boldsymbol{c}=$ $\left.c^{\prime}+a^{*} b\right)=0.427+0.16443=$ 0,59143

Pengaruh langsung yang lebih besar dibanding pengaruh tidak langsung membuktikan bahwa konsep diri dibidang akademik hanya memediasi sebagian (partial mediation) dari pengaruh persepsi atas keterlibatan orang tua terhadap hasil belajar.

Hasil penelitian ini sesuai dengan hasil temuan Kim (2002), Van Voorhis (2003) dan Lamborn et al (1992) yang menyatakan bahwa siswa mencapai hasil yang lebih tinggi ketika orang tuanya memberi bantuan dan saat orang tua dan anak bersama-sama dalam mengambil sebuah keputusan (misal, memilih kursus yang akan diambil) akan berdampak positif

\section{Ekuitas - Jurnal Pendidikan Ekonomi}

pada capaian akademik siswa. Hasil penelitian ini juga sejalan dengan hasil penelitian Harris \& Goodall (2008), O'Bryan et al (2009), Broh (2002), Carpenter \& Ramirez (2007), Epstein (1988), Patterson (1986), Grolnick, Ryan, \& Deci (1991), Grolnick \& Slowiaczek (1994) yang menyatakan bahwa keterlibatan orangtua di sekolah berdampak langsung pada keberhasilan siswa dengan peningkatan pada nilai dan mengurangi resiko siswa drop-out. Keterlibatan orang tua dikaitkan dengan hasil sekolah siswa melalui pengembangan/ pembangunan keterampilan kognitif siswa yang dibutuhkan untuk tugas-tugas akademik sekolah atau mempengaruhi motivasi dan sikap siswa dalam merangsang upaya internal untuk mencapai tingkat akademik yang bagus.

Dalam analisis data secara deskriptif menunjukkan rata-rata siswa yang menjadi responden dalam penelitian ini memiliki persepsi atas keterlibatan orang tua dalam pendidikan yang tinggi, dan perolehan skor hasil belajar mereka rata-rata 81,17 sehingga jumlah responden penelitian yang lulus atau memenuhi kriteria ketuntasan minimal (KKM) adalah sebanyak $78,42 \%$. Hal ini tentu sejalan dengan hasil pengujian hipotesis yang menunjukkan bahwa persepsi atas keterlibatan orang tua berpengaruh positif signifikan terhadap hasil belajar.

Sehingga dapat disimpulkan bahwa hasil pengujian hipotesis dalam penelitian ini mendukung teori yang dikemukakan oleh Epstein (1988) yang menyatakan bahwa keterlibatan orang tua berdampak positif pada pencapaian keberhasilan pendidikan siswa. Selain itu hasil penelitian ini juga sejalan dengan temuan penelitian sebelumnya, atau dengan kata lain

69 | Arlef Rafsanjan i 


\section{Vol. 4 No. 2 Desember 2016}

temuan dalam penelitian ini konsisten dengan teori dan pengujian empiris yang telah dikemukakan sebelumnya. Jadi penelitian ini telah membuktikan bahwa keterlibatan orang tua merupakan salah satu factor yang memp Hasil penelitian ini menunjukan bahwa konsep diri dibidang akademik memediasi sebagian (partial mediation) dari pengaruh persepsi atas keterlibatan orang tua terhadap hasil belajar. Sehingga hal ini menjawab masalah inkonsistensi beberapa penelitian yang menyatakan bahwa tidak terdapat pengaruh signifikan dari persepsi atas keterlibatan orang tua terhadap hasil belajar dan bahkan terdapat hubungan negatif diantara dua variabel tersebut (Bobbett et al., 1995; Keith et al,. 1986; Okpala dan Smith, 2001; Deslandes et al., 1997; Sui-Chu dan Willms, 1996). Inkonsistensi temuan tersebut diduga oleh Keith et al., (1986) dan El-Fattah (2006) akibat adanya variabel lain yang berperan sebagai mediator, dan kemudian terjawab dalam penelitian ini bahwa salah satu variabel yang menjadi mediator tersebut adalah konsep diri dibidang akademik.

Hasil ini juga membuktikan kebenaran dari dugaan Eccles (2005) bahwa pengaruh keterlibatan orang tua terhadap hasil belajar di mediasi oleh konsep diri siswa dalam kemampuan akademiknya. Oleh karena itu hasil penelitian ini juga memperkuat teori the expectancy-value model of achievement yang dikemukakan oleh Eccles (1983) dan Wigfield (1994), yaitu keinginan untuk menggapai kesuksesan salah satunya dipengaruhi oleh kepercayaan atas kemampuan yang dimiliki yang selanjutnya dikenal dengan istilah konsep diri. Selanjutnya, konsep diri salah satunya dipengaruhi oleh

\section{Ekuitas - Jurnal Pendidikan Ekonomi}

keterlibatan orang tua.

Hasil penelitian ini juga

sejalan dengan hasil penelitian sebelumnya yang menemukan bahwa keterlibatan orang tua berpengaruh positif pada konsep diri yang dimiliki siswa (Juang dan Silbereisen's, 2002; Hung, 2005; Grolnick dan Slowiaczek, 1994, Marchant et al., 2001; GonzalezDeHass et al., 2005), dan konsep diri siswa secara langsung mempengaruhi prestasi akademik yang dicapai (Guay et al., 2003; Moreano, 2004; Marsh, 2006; Pajares, 2000).

Seperti yang telah dibahas sebelumnya bahwa rata-rata siswa memiliki persepsi atas keterlibatan orang tua dalam pendidikan yang tinggi, dan perolehan skor hasil belajar mereka rata-rata 81,17 sehingga jumlah responden penelitian yang lulus atau memenuhi kriteria ketuntasan minimal (KKM) adalah sebanyak $78,42 \%$. Dalam analisis data secara deskriptif juga menunjukkan ratarata responden memiliki konsep diri dibidang akademik yang tinggi, hal ini menunjukan bahwa siswa yang menjadi responden penelitian merasa memiliki kemampuan akademik yang tinggi. Hal ini terlihat pada indicator academic confidence dan academic effort yang rata-rata siswa (responden penelitian) cukup percaya diri (confidence) bahwa kemampuan akademik yang dimilikinya dirasa cukup baik dan merasa memiliki komitmen dan telah berusaha untuk melakukan tugasnya sebagai siswa dengan baik. Dari paparan tersebut terlihat bahwa siswa yang memiliki persepsi atas keterlibatan orang tua yang tinggi akan akan memiliki konsep diri dibidang akademik yang tinggi juga dan pada akhirnya akan berdampak positif pada hasil belajar yang diperoleh. Hal ini tentu sejalan dengan hasil pengujian hipotesis

70 | Arlef Rafsanjan i 


\section{Vol. 4 No. 2 Desember 2016}

yang menunjukan bahwa konsep diri dibidang akademik berfungsi secara signifikan sebagai variabel mediator dari pengaruh persepsi atas keterlibatan orang tua terhadap hasil belajar pengaruhi pencapaian hasil belajar siswa disekolah.

\section{SIMPULAN DAN SARAN}

Berdasarkan hasil penelitian yang telah dilakukan diperoleh kesimpulan yaitu terdapat pengaruh positif signifikan persepsi atas keterlibatan terhadap hasil belajar ekonomi pada siswa SMAN se Kota Malang, demikain halnya variabel konsep diri dibidang akademik berfungsi secara signifikan sebagai variabel mediator dari pengaruh persepsi keterlibatan orangtua terhadap hasil belajar ekonomi pada siswa SMA. Namun peran variabel konsep diri dibidang akademik dalam model penelitian ini merupakan partial mediation variable atau merupakan variabel yang memediasi sebagian dari pengaruh persepsi atas keterlibatan orang tua terhadap hasil belajar sehingga ada variable lain yang juga turut memediasi hubungan kausal tersebut yang tidak diteliti dalam model ini

Hasil penelitian ini merekomendasikan beberapa saran, yaitu bahwa salah satu factor yang berpengaruh pada hasil belajar adalah keterelibatan orang tua dan konsep diri dibidang akademik, oleh karena itu hendaknya siswa meningkatkan hubungan komunikasi dan kerjasama dengan orang tua agar membentuk konsep diri dibidang akademik yang positif sehingga berdampak positif juga pada hasil belajar disekolah. Hasil penelitian yang menunjukan bahwa persepsi siswa atas keterlibatan orang tua berdampak positif pada konsep diri dibidang akademik dan hasil belajar siswa,maka hendaknya orang tua

\section{Ekuitas - Jurnal Pendidikan Ekonomi}

semakin menghadirkan diri dalam kehidupan pendidikan siswa dalam bentuk dukungan, bantuan dan komunikasi yang diarahkan untuk menumbuhkan konsep diri anak.

\section{DAFTAR PUSTAKA}

Azwar, S. 2009. Sikap manusia: toeri dan pengukurannya. Pustaka Pelajar, Yogyakarta

Bandura, A. (1986). Social foundations of thought and action: $A$ social cognitive theory. Prentice- Hall, Englewood Cliffs, NJ.

Bandura, A., Adams, N. E., \& Beyer, J. (1997). Cognitive processes mediating behavioral change. Journal of Personality and Social Psychology, 35, 125-139.

Baron, RM \& Kenny, DA. 1986. The moderator-mediator variable distinction in social psychological research:Conceptual, strategic, and statistical considerations. Journal of Personality and Social Psychology;51:1173-1182.

Bloom,B.S. 1980. The new direction for educational research: alterable variables. Phi Delta Kappan, 61:382-385.

Broh, B. A. 2002. Linking extracurricular programming to academic achievement: Who benefits and why? Sociology of Education, 75(1), 69- 91.

Bobbett, G. C., French, R. L., Achilles, C. M. and Bobbett, N. C.1995. An analysis of Nevada's report cards on high school. Paper presented at the annual meeting of the Mid-South Educational Research Association Annual Meeting, Biloxi, MI

Brooks, J.G., \& Brooks, M.G. 1993. In Search of understanding: 
Vol. 4 No. 2 Desember 2016

The Case for constructivist classrooms. Virginia: Association for Supervision and Curriculum Development.

Brooks, W.D., Emmert, P. 1976. Interpersonal Community. lowa: Brow Company Publisher.

Bronfenbrenner, U. 1986. Ecology of family as a context for human development: Research perspectives. Development Psychology, 22, 723-742.

Bulu, G Yohanes.. 2010. Penemuan Diri (Self Invention). (online) (http://magammar.blogspot.c om/2010/01/penemuan-diriself-avention.html) diakses 25 Juli 2012

Carpenter, D., \& Ramirez, A. 2007. More than one gap: Dropout rate gaps between and among black, hispanic, and white students. Journal of Advanced Academics, 19(1): 32-64.

Cervone, B.T.and K. O'leary. 1982. Aconceptual framework for parent involvement. Educational Leadership, 40(2), 48-49

Chapman, K. 1996. Entry qualifications, degree results and value-added in UK Universities. Oxford Review of Education, 22(3), 251264.

Cho, Hichang; Geri Gay; Barry Davidson; Anthony Ingraffea. 2005. Social networks, communication styles, and learning performance in a CSCL community

Deslandes, R., Royer, E., Turcotte, D. and Bertrand, R. 1997. School achievement at the secondary level: Influence of parenting style and parent involvement in schooling.

\section{Ekuitas - Jurnal Pendidikan Ekonomi}

McGill Journal of Education, 32, 191-207.

Dimyati dan Mujiono. 1994. Belajar dan Pembelajaran. Jakarta: Departemen Pendidikan dan Kebudayaan

Dimyati. 1999. Belajar dan Pembelajaran. Jakarta: Rineka Cipta.

Djamarah, S. Bahri dan Aswan Zain. 1997. Strategi belajar mengajar. Jakarta: Rineka Cipta

Djamarah, Saiful Bahri. 2002. Psikologi Belajar. Jakarta: Rineka Cipta

Eccles, J. S. 2005. Studying the development of learning and task motivation. Learning and Instruction, 15, 161171.

Eccles, J. S. \& Davis-Kean, P. E. 2005. Influences of parents' education on their childrens' educational attainments: the role of parent and child perceptions. London Review Education, 3(3), 191-204

Eccles, J. S. \& Wigfield A. 2002. Motivational Beliefs, Values, And Goals. Annu. Rev. Psychol. 53:109-32

Eccles, J.S. 1983. Expectancies, values and academic behaviors. In J.T. Spence (Ed.). Achievement and achievement motives (pp.75146). San Francisco: Freeman

Elbaum, B. \& Vaughn, S. 2001. School-based interventions to enhance the self-concept of students with learning disabilities: A Meta-Analysis. Elementary School Journal, 101(3), 303-329.

El-Fattah, Sabry MA. 2006. The relationship among Egyptian adolescents' perception of parental involvement, academic achievement, and 
Vol. 4 No. 2 Desember 2016

achievement goals: A mediational analysis. International Education Journal, 7(4), 499-509

Epstein, J. L. 1988. How do we improve programs for parent involvement? Educational Horizons, 66, 15-11.

Epstein, J. L.(1991) Effects on students'achievement of teachers'practices of parent involvement. Advances in reading/language research: Literacy through family, community and school interaction. 5, 261-276. Greenwich, CT: Jai Press.

Epstein. J. L. 1995. School /family/community

partnerships: Caring for the children we share. Phi Delta Kappan, 76, 701-712.

Galal-El-Dean, M. 1994. Parents and teachers effects on high school students' achievement motivation. Unpublished doctoral dissertation, University of Missouri, Missouri, USA.

Gagne, Robert. 1983. The Condition of Learning. Japan: Holt Saunders.

Gonzalez, A., \& Wolters, C. 2006. The relation between perceived parenting practices andachievement motivation in mathematics. Journal of Research in Childhood Education,21, 203-217.

Goyette, K., and Y.Xie. 1999. Educational expectations of Asian American youths: Determinants and ethnic differences. Sociology of Education, 72(1), 22-36.

Green, J., Nelson, G., Martin, A.J., \& Marsh, H. 2006. The causal ordering of selfconcept and academic motivation and its effect on academic achievement.

\section{Ekuitas - Jurnal Pendidikan Ekonomi}

International

Education Journal, 7(4), 534-546

Grolnick, W. and Slowiaczek, M. 1994. Parents' involvement in children's schooling: A multidimensional

conceptualization and motivational model. Child Development, 65, 237-252.

Grolnick, W., Ryan, R. and Deci, E. 1991. Inner resources for school achievement: Motivational mediators of children's perceptions of their parents. Journal of Educational Psychology, 83, 508-517.

Guay, F., Marsh, H. W., \& Boivin, M. 2003. Academic selfconcept and achievement: Developmental perspective on their causal ordering. Journal of Educational Psychology, 95, 124-136.

Gunarsa, Singgih D. 1995. Psikologi Perkembangan Anak dan Remaja. Jakarta: Gunung Mulia

Gurney, P. 1988. Self-Esteem in Children with Special Educational Needs. London: Routledge.

Hamalik, Oemar. 2003. Proses Belajar Mengajar. Jakarta: PT.Bumi Aksara.

Harris, A., \& Goodall, J. 2008. Do parents know they matter? Engaging all parents in learning. Educational Research, 50, 277-289.

Harter, S. 1998. The development of self-representations. In Damon, W., \& Eisenberg, N. (ed.), Handbook of child psychology, 3 (5), 553-617. New York: John Wiley and Sons.

Hung, Chih-Lun. 2005. Family Background, Parental Involvement and Environmental Influences on Taiwanese Children. The 
Vol. 4 No. 2 Desember 2016

Alberta Journal of

Educational Research.

51(3), 261-276

Juang, L.P., \& Silbereisen, R.K. 2002. The relationship between adolescent academic capability beliefs, parenting, and school grades. Journal of Adolescence, 25,3-18.

Keith, T. Z., Reimers, T. M., Fehrmann, P. G., Pottebaum, S. M. and Aubey, L. W. 1986. Parental involvement, homework, and TV time: Direct and indirect effects on high school achievement. Journal of Educational Psychology, 78, 373-380.

Kenny, David A. 2012. Mediation. (online)

http://davidakenny.net $/ \mathrm{cm} / \mathrm{m}$ ediate.htm\#BK. Diakses 14 Desember 2012.

Keng-Soon, S., \& Bonk, C. J. 1998. Interaction: What does it mean in online distance education. Paper presented at the 10th annual EDMEDIA/ED-TELECOM 98 World Conference on Educational Multimedia and Hypermedia \& World Conference on Educational Telecommunications.

Freiburg-Germany.

Kim,_Eunjung. 2002. The relationship between parental involvement and children's educational achievement in the Korean immigrant family . Journal of Comparative Family Studies. 33.4 p529

Kinicki, Angelo dan Robert Kreitner. 2003. Organizational behavior Key Concept, Skills \& Best Pratices. Boston: Mc.Graw Hill

Krech, David , Richard S. Crutchfield, Norman Livson.

\section{Ekuitas - Jurnal Pendidikan Ekonomi}

1973. Elements of Perception. New York: Knopf publishing

Kuh et al. 2006. What Matters to Student Success: A Review of the Literature, Commissioned Report for the National Symposium on Postsecondary Student Success.

Lamborn, S., Brown, B., Mounts, N. and Steinberg, L. 1992. Putting school in perspective: The influence of family, peers, extracurricular participation, and part-time work on academic engagement. In F. Newmann (Ed.), Student Engagement and Achievement in American Secondary Schools(pp. 153181). New York: Teachers College.

Liu, W.C., \& Wang, C.K.J.W. 2005. Academic Self-Concept: A Cross-Sectional Study of Grade and Gender Differencea in a Singapore Secondary School. Asia Pacific Education Review, Vol. 6, 20-27

Marchant, G.J., Paulson, S.E., \& Rothlisberg, B.A. 2001. Relations of middle schoolstudents' perceptions of family and school contexts with academic achievement. Psychology in the Schools, 38(6), 505-519.

Marjoribanks, K. 1994. Family, schools and children's learning: A study of children's learning environments. International Journal of Educational Research, 21, 439-555.

Marjoribanks, K. 2002. Family and school capital: Towards a context theory of students' school outcomes. Dordrecht,

74 | Arlef Rafsanjan i 
Vol. 4 No. 2 Desember 2016

Netherlands: Kluwer Academic

Marsh, H. W. 2006. Self-concept theory, measurement and research into practice: The role of self-concept in educational psychology. Unpublished manuscript, British Psychology Society, 25th Vernon- Wall lecture.

Marsh, H. W., Byrne, B. M., \& Yeung, A. S. 1999. Causal ordering of academic selfconcept and achievement: Reanalysis of a pioneering study and revised recommendations.

Educational Psychologist, 34, $154-157$.

Marsh, H. W., Craven, R., \& Debus, R. 1999. Separation of competency and effect components of multiple dimensions of academic self-concept: A developmental perspective. Merrill-Palmer Quarterly, 45, 567-601.

Marsh, H. W., Ellis, L., \& Craven, R. G. 2002. How do pre-school children feel about themselves? Unravelling measurement and multidimensional selfconcept structure. Developmental Psychology, 38,376-393.

Mc. Shane. Steven L. Mary Ann Von Glinow. 2000. Organizational Behavior. Boston: Irwin McGraw Hill

Miedel, W. T. and Reynolds, A. J. 1999. Parent involvement in early intervention for disadvantaged children: Does it matter? Journal of School Psychology, 37, 379402.

Moreano, Giovanna. 2004. The Relationship Between Academic Self-Concept, Causal Attribution For

\section{Ekuitas - Jurnal Pendidikan Ekonomi}

Success and Failure, and Academic Achievement in Pre-Adolescents. Dalam H.W. Marsh, J. Baumert, G.E. Richards, dan U. Trautwein (Eds.), SelfConcept, Motivation and Identity: Where to from here? (hlm. Proceedings of The Third Intenational Biennial SELF Research Conference. Berlin: Max Planck Institute for Human Development.

O'Bryan, S.T., Braddock, J.H., \& Dawkins, M.P. 2009. An examination of the effectsof school-based varsity sport participation and parental involvement on male academic behaviors. Challenge, 14, 1-27.

Okpala, C. O., Okpala, A. O. and Smith, F. E. 2001. Parental involvement, instructional expenditures, family socioeconomic attributes, and student achievement. Journal of Educational Research, 95, 110-115.

Pajares,F. 2000. Current derection in self-efficacy reseach. In M. Macrh \& P. R. Pintridh (eds). Advances in motivation and achivement. http:www.des.employ/mfp/ba ntncy.html

Patterson, G. R. 1986. Performance models for antisocial boys. American Psychologist, 41, 432-444.

Potter, J, Robins, R. W ., Trzesniewski, K. H., Tracy, J. L., \& Gosling, S. D. 2002. Global self-esteem across the life span. Psychology andAging, 17,423-434

Preacher, Kristopher J \& Geoffrey J. Leonardelli. 20. Calculation for the Sobel test: An interactive calculation tool for mediation tests. (Online).

75 | Arlef Rafsanjan i 
Vol. 4 No. 2 Desember 2016

http://quantpsy.org/sobel/sob el.htm. Diakses 5 April 2013

Reigeluth, C.M. 1983. InstructionalDesign Theories and Models (vol 1). Mahwah, NJ: Lawrence Erlbaum Associates.

Robbins, Stephen P. 2007. Perilaku Organisasi Buku 1. Jakarta: Salemba Empat

Sadirman, AM. 2007. Interaksi dan Motivasi Belajar Mengajar. Jakarta: Rajawali Pers

Seginer, $\mathrm{R}$. 1983.

Parents'educational expectations and children's academic achievements: A literature review. MerrillPalmer Quarterly, 29, 1-23.

Shavelson, R. J., Hubner, J. J., \& Stanton, G. C. 1976. Selfconcept: Validation of construct interpretations. Review of Educational Research, 46, 407-441.

Shumow, L., \& Miller, J. D. 2001. Parents' at-home and atschool academic involvement with young adolescents. Journal of Early Ad-olescence, 21,68-91.

Slameto. 2003. Belajar dan faktorfaktor yang mempengaruhinya. Jakarta: Rineka Cipta.

Soemanto, Wasty. 1984. Psikologi Pendidikan. Jakarta: Bina Aksara

Sudjana, Nana. 2004. Dasar-dasar Proses Belajar Mengajar. Bandung: Sinar Baru

Sui-Chu, E. and Willms, J. D. 1996. Effects of parental involvement on eighth grade achievement. Sociology of Education, 69, 126-141.

Surya, M. 1987. Psikologi Pembelajaran dan Pengajaran. Bandung: Pustaka Bani Quraisy

\section{Ekuitas - Jurnal Pendidikan Ekonomi}

Suryabrata, Sumadi. 1984. Psikologi Pendidikan. Jakarta: Rajawali Press

Snelbecker, Glenn E. 1974. Learning theory, instructional theory, and psychoeducational design. New York : McGraw-Hill

Syah, Muhibbin. 2002. Psikologi Belajar. Jakarta: Rajawali Press

Trautwein, U., Ludtke, O., Koller, O., \& Baumert, J. 2006. Self -esteem, academic self concept, and achievement: How the learning environment moderates the dynamics of self concept. Journal of Personality and Social Psychology, 90, 334349.

Tu'u, Tulus. 2004. Peran Disiplin pada Perilaku dan Prestasi Siswa. Jakarta: Grasindo

Van Damme, J, M-C. Opdenakker, B. De Fraine, and W. Mertens. 2002. Academic Self-Concept and Academic Achievement: Cause and Effect. International Education Journal, 5(3), 341-354

Van Voorhis, F. L. 2003. Interactive homework in middle school: Effects on family involvement and science achievement. Journal of Educational Research, 96, 323-338.

Wassenaar, Carolyn M. Veldhuizen . 1994. The Relationship Between Academic Confidence and Academic Achievement of Selected First Time Students at Grand View College. Unpublished Thesis, Drake University, lowa, USA

West, C. K., Fish, J. A., \& Stevens, R. J. 1980. General selfconcept, self-concep 
Vol. 4 No. 2 Desember 2016

academic ability and school achievement: implication for causes of self concept. The Australian Journal Education, 24(2): 194-213

Wigfield, A. 1994. Expectancy-value theory of achievement motivation: A developmental perspective. Educational Psychology Review, 6,4978.

Winkel, W.S. 2005. Psikologi Pengajaran. Edisi revisi. Jakarta: Gramedia

Wozniak, Helen dan Sue Silveira. 2004. Online Discuccion: Promoting efective student to student interaction. Perth: Proceedings of the 21st ASCILITE Conference

Zimmerman, M. A., Copeland, L. A., Shope, J. T. and Dielman, T. E. 1997. A longitudinal study of self-esteem: implications for adolescent development. Journal of Youth and Adolescence, 26,2,117-141. 